\title{
Slipped Capital Femoral Epiphysis (SCFE) Coxa Vara Adolescentium (CVA)
}

\section{Gharaibeh $\mathrm{A}^{1 *}$ and Al Wadyia $\mathrm{A}^{2}$}

${ }^{1}$ Orthopaedic Surgeon, Assistant professor, Department of Orthopaedics and musculoskeletal trauma, UPJS, Slovakia

${ }^{2}$ Orthopaedic Surgeon, Department of Orthopaedics, Royal Derby Hospital, UK

*Corresponding author: Dr. Ahmad Gharaibeh, MPH, PhD, Orthopaedic Surgeon, Assistant professor, Department of Orthopaedics and musculoskeletal trauma, UPJS, UNLP, Kosice, Slovakia, Tel: +421948612693; Email: gharaibeh@seznam.cz

\section{Abstract}

Slipped femoral capital epiphysis is considered to be one of the most destructive conditions of hip joint during adolescence. The epiphysolysis of the femoral head was first defined in 1572 by the French surgeon Abrois Paré (1510 1590). The first authentic traumatic epiphysesolysis of the femoral head was described by Brousseau in 1867. It was in a 15-year-old boy with multiple injuries after trauma with heavy carriage. Death occurred in a few hours, and was discovered by post-mortem examination. Complete separation of epiphysis of the femur head was found.

The first mention of a non-traumatic form of epiphysolysis occurred in a fourteen years old boy later. In 1881, Fiorani reported fifteen cases of distorted hip joint with impaired adduction in children. He described the deformity as a bend of the proximal part of the femur, which was based on rickets. With a high probability, some individuals were coxa vara adolescentium.

The first complete description of the disease was given by E Müller (1888) in his work "About the bending of the femoral neck in the growth age" Coxa vara adolescentium (CVA), epiphysesolysis of femural head or slipped femoral capital epiphysis represents a serious hip disease in the pubescent age at which the femoral proximal growth plate loses its strength and influence mechanical forces, caused mainly by excessive body weight, the non-traumatic epiphysesolysis will occur. Symptoms like pain and twisting are initially vague, but they tend to escalate over time.

The incidence of this disease is 0.1 per one million, affect male more than female 2:1,4 in the rapid growth period 10-16 years old. Childhood obesity is the common cause of Slipped femoral capital epiphysis, then endocrine disorders and Down syndrome.

Slipped femoral capital epiphysis has three grades first up to 33 degrees of slippage, second grade from $34-50 \%$ of slippage and the third degree more than $50 \%$. 


\section{Journal of Orthopedics \& Bone Disorders}

Slipped femoral capital epiphysis, represents a serious disease of the puberty in the pubescent age at which the femoral proximal growth plate loses its strength and influence mechanical forces, caused mainly by excessive body weight, will occur non-traumatic epiphysesolysis. Symptoms like pain and limping are initially vague, but they tend to escalate over time.

Keywords: Slipped Capital Femoral Epiphysis; Fixation; Reduction; History

\section{Prognosis}

The most important criteria that determine the prognosis of this disease is the value of Southwick angle. Patients with mild epiphysolysis ( $<30$ degrees) have good results prognosis compared to patients who develop mild to severe form. Patients with a greater slip angle have a much higher risk of developing $\mathrm{OA}$ at a later age [1]. Although several forms of epiphysolysis have potential bone remodelling due to increased mechanical abrasion at bone marrow impingement such remodelling is not sufficient and the risk of developing $\mathrm{OA}$ is therefore at impingement cranially [2-6].

\section{Conclusion}

Epiphysesolysis of the femural head is still very serious at present and a problem in paediatric orthopaedics, either due to delayed diagnosis or incorrect treatment method selected. This disease occurs more frequently in boys aged from 13 to 15 years. The increasing incidence of the disease is due to an increase in BMI in children. This suggests that obesity is the most serious risk factor for slipping head femur.

The first choice in the treatment of this disease is surgical treatment by fixation with cannulated $1 / 3$ partial threaded screws or kirchner threaded wires. For most of the patients with stable form of epiphysolysis, in situ fixation is sufficient with cannulated screw. This applies to mild ( $<30$ degrees) as well as moderate form (30-60 degrees). For stable slides where the slip angle is greater than $60^{\circ}$ degrees, the surgeon should consider performing Dunne's osteotomy. In patients with any degree of unstable epiphysolysis who are admitted to 24 hours after the onset of symptoms, a slight reduction should be performed with traction table. The aim of this reduction is to improve the relationship and position of the head and neck of the femur, and thus reduce the slip angle. If the presentation of a patient with an unstable form of epiphysolysis is delayed, after 24 hours after the onset of symptoms, it is recommended to wait at least for surgical treatment 2 to 3 weeks to minimize the risk of AVN. During this time the patient should have skin traction.

Therefore, the choice of method depends not only on the equipment of the operating room, but also on the skills of the surgeon to perform various modern methods. To choose the right surgical methods it is important to evaluate possible contraindications, because of the possibility of complications during or after surgery.

\section{References}

1. Key John Albert (2013) The Classic: Epiphyseal Coxa Vara or Displacement of the Capital Epiphysis of the Femur in Adolescence. Clinical Orthopaedics and Related Research® 471(7): 2087-2117.

2. Dungl Pavel (2014) Orthopedics. 2nd, revised and supplemented edition. Grada.

3. Örtegren J (2018) Slipped Capital Femoral Epiphysis. Growth, Remodeling and Cartilage Quality after Unthreaded Fixation. Faculty of Medicine, Lund University, Lund, pp: 76

4. Akiyama M, Nakashima $\mathrm{Y}$, Kitano T, Nakamura T, Takamura K, et al. (2013) Remodelling of femoral head-neck junction in slipped capital femoral epiphysis: a multicentre study. Int Orthop 37(12): 2331-2336.

5. Matsushita $\mathrm{M}$, Mishima $\mathrm{K}$, Iwata $\mathrm{K}$, Hattori $\mathrm{T}$, Ishiguro N, et al. (2017) Percutaneous pinning after prolonged skeletal traction with the hip in a flexed position for unstable slipped capital femoral epiphysis. Medicine 96(19): e6662.

6. Beaulé PE, Singh A, Poitras S, Parker G (2015) Surgical dislocation of the hip for the treatment of prearthritic hip disease. J Arthroplasty 30(9): 15021505. 